\title{
Formononetin Promotes Cell Cycle Arrest via Downregulation of Akt/Cyclin D1/CDK4 in Human Prostate Cancer Cells
}

\author{
Tianyu Lia Xinge Zhao ${ }^{\mathrm{b}}$ Zengnan Mo $\mathrm{M}^{\mathrm{a}}$ Weihua Huang ${ }^{\mathrm{c}}$ Haibiao Yan ${ }^{\mathrm{a}}$ Zhian Ling \\ Yu Yec
}

aInstitute of Urology and Nephrology, First Affiliated Hospital of Guangxi Medical University, Nanning, bSchool of Basic Medical Sciences, Guilin Medical University, Guilin, 'Department of Emergency, Western Hospital, First Affiliated Hospital of Guangxi Medical University, Nanning, China

\section{Key Words}

Formononetin $\cdot \mathrm{CDK} 4 \cdot$ Cyclin D1 $\cdot$ Akt $・$ Prostate cancer

\begin{abstract}
Background: Formononetin is an O-methylated isoflavone isolated from the root of Astragalus membranaceus. It has already been reported that formononetin could inhibit cell proliferation and induce cell apoptosis in several cancers, including prostate cancer. This study aimed to further investigate whether cell cycle arrest is involved in formononetin-mediated antitumor effect in human prostate cancer cells, along with the underlying molecular mechanism. Methods: Human prostate cancer cells PC-3 and DU145 were respectively treated with various concentrations of formononetin. The inhibitory effect of formononetin on proliferation of prostate cancer cells was determined using MTT assays and flow cytometry. Next, formononetininduced alterations in cyclin D1, CDK4 and Akt expression in PC-3 cells were detected by real-time PCR and western blot. Results: Formononetin dose-dependently inhibited prostate cancer cell proliferation via the induction of cell cycle arrest at G0/G1 phase in vitro, which was more evident in PC-3 cells. Meanwhile, concomitant with reduced phosphorylation of Akt in PC-3 cells, formononetin remarkably downregulated expression levels of cyclin D1 and CDK4 in a dose-dependent manner. More interestingly, in the in vivo studies, formononetin showed a noticeable inhibition of tumor growth in recipient mice. Conclusion: Formononetin could exhibit inhibitory activity against human prostate cancer cells in vivo and in vitro, which is associated with G1 cell cycle arrest by inactivation of Akt/cyclin D1/CDK4. Therefore, formononetin may be used as a candidate agent for clinical treatment of prostate cancer in the future.
\end{abstract}

Copyright $\odot 2014$ S. Karger AG, Basel 


\section{Introduction}

In spite of recent advances in molecular diagnostic technologies and new drug development, prostate cancer (PCa) remains the most common cancer in men older than 50 years of age, and the second leading cause of cancer-related deaths in men in America [1-3]. Until now, the etiology of PCa has not been entirely elucidated, which may involve age, ethnicity, family history of prostate cancer, genetic susceptibility and lifestyle factors [4]. The incidence of PCa was reported to be much higher in North America than in Western Europe, Oceania, and Asia [5]. Moreover, men from Asia are likely to acquire an increased incidence of PCa after emigration to America, suggesting that diet diversity may play a major role in the initiation, promotion, and progression of PCa [6]. Considering the difference in soy food consumption between Asian and Western countries, researchers began to focus on whether soy could contribute to the lower occurrence of PCa in Asia [7].

Phytoestrogens, sometimes called dietary estrogens, are present at high concentrations in many soy products. Owing to the high structural similarity with estrogen, phytoestrogens may have either estrogenic or antiestrogenic effects. Previous studies have demonstrated that some phytoestrogens, such as genistein, could inhibit growth of PCa cells in vitro, indicating the antiestrogenic activity of phytoestrogens on prostate cancer [8]. Formononetin $\left(\mathrm{C}_{16} \mathrm{H}_{12} \mathrm{O}_{4}\right)$ is a traditional Chinese herbal medicine isolated from red clover, and distributed extensively in Guangxi Province of Southern China [9]. As a typical phytoestrogen, formononetin has been demonstrated to possess a wide range of biological activities including antioxidant, antiviral and cardioprotective effects [10]. Remarkably, some other studies reported formononetin-induced tumor cell apoptosis in some cancer types in vitro and in vivo [11-14]. For instance, it was shown that formononetin could induce mitochondrial apoptosis in PCa cells via downregulation of IGF-1/IGF-1R signaling pathway, implying the potential application of formononetin in antitumor therapy against prostate cancer [15]. In addition, our previous studies have confirmed the prevention of breast carcinogenesis by formononetin-triggered cell cycle arrest at G0/G1 phase [16]. Therefore, we postulated that formononetin may likewise inhibit growth of PCa through cell cycle arrest. Moreover, in order to better determine the molecular mechanism of formononetin, we here explored the roles of cyclin D1, CDK4 and Akt in prostate neoplasia.

\section{Materials and Methods}

\section{Drugs and animals}

Formononetin $\left(\mathrm{C}_{16} \mathrm{H}_{12} \mathrm{O}_{4}\right.$, purity $>98 \%$, verified by high performance liquid chromatography) was purchased from Phytomarker Company (Tianjin, China). Formononetin was dissolved in dimethyl sulfoxide (DMSO), and then diluted with RPMI-1640 to the desired final concentration. The final concentration of DMSO in the assay was under $0.1 \%(\mathrm{v} / \mathrm{v})$.

\section{Cell culture}

Human prostate cancer cell lines (PC-3, DU145) were obtained from American Type Culture Collection (Manassas, VA, USA). Cells were cultured in RPMI-1640 medium containing 10\% fetal bovine serum (FBS) and $1 \%$ penicillin-streptomycin (Invitrogen, Carlsbad, CA) in a humidified atmosphere of $5 \% \mathrm{CO}_{2}$ at $37^{\circ} \mathrm{C}$.

\section{MTT assay}

Cells were seeded into 96 -well plates $\left(4 \times 10^{3}\right.$ cells per well) and cultured for $24 \mathrm{~h}$. After incubation with increasing concentrations of formononetin $(0,10,20,30,40,60,80,100 \mu \mathrm{M})$ for $48 \mathrm{~h}$, cells were exposed to MTT ( $5 \mathrm{mg} / \mathrm{mL}$ ) in phosphate buffered saline (PBS). Subsequently, the medium was removed and the formed formazan was dissolved in $150 \mu \mathrm{L}$ dimethy1 sulfoxide (DMSO, Sigma). The optical density (OD) for each well was measured at $570 \mathrm{~nm}$ by a microculture plate reader (Bio-Rad, USA). 


\section{Flow cytometry assay}

After $48 \mathrm{~h}$ treatment of formononetin $(0,20,40$ and $80 \mu \mathrm{M}), \mathrm{PC}-3$ cells were harvested and fixed in ice-cold $70 \%$ ethanol at $4^{\circ} \mathrm{C}$ for $30 \mathrm{~min}$. Then cells were washed with PBS, resuspended in $500 \mu \mathrm{L}$ of binding buffer, and stained with annexin V-FITC and propidium iodide (PI) for $30 \mathrm{~min}$ in the dark at $37^{\circ} \mathrm{C}$. The Annexin V-FITC apoptosis detection kit (Boster, China) was used to determine the percentage of cells in G0/ G1, S and G2/M cell-cycle phases according to the manufacturer's instruction.

\section{Real-time PCR assay}

PC-3 cells were treated with different concentrations of formononetin $(0,25,50$ and $100 \mu \mathrm{M})$ for 48 h. Then total RNA was extracted from cells using the TRIzol reagent (Gibco-BRL, USA) according to the manufacturer's instruction. The RNA pellet was washed with ice-cold $75 \%$ ethanol, air-dried and dissolved into RNase-free water. cDNA was reverse-transcribed from total RNA following the RevertAid First Strand cDNA Synthesis Kit (Fermentas, USA). Amplification was conducted with an initial 10 min step at $95^{\circ} \mathrm{C}$, followed by 35 cycles of $94^{\circ} \mathrm{C}$ for $30 \mathrm{~s}, 55^{\circ} \mathrm{C}$ for $30 \mathrm{~s}$, and then $72^{\circ} \mathrm{C}$ for $45 \mathrm{~s}$. PCR products were separated on $1 \%$ agarose gel stained with ethidium bromide. And data were analyzed by a comparative threshold (CT) cycle method (Bulletin, PE Applied Biosystems). $\beta$-actin was used as an internal control.

\section{Western blot assay}

PC-3 cells were incubated with various concentrations of formononetin $(0,20,40$ and $80 \mu \mathrm{M})$ for $48 \mathrm{~h}$. Cell extracts were prepared in ice-cold lysis buffer. Then equivalent amounts of protein were separated by sodium dodecyl sulfate-polyacrylamide gel electrophoresis (SDS-PAGE), transferred onto polyvinylidene difluoride (PVDF) membrane (Millipore, Bedford, MA, USA). After blocking with TBST (Tris-buffered solution, $0.05 \%$ Tween 20, pH 7.6) containing 5\% nonfat milk for $2 \mathrm{~h}$, the membranes were immunoblotted with various primary antibodies as indicated: Anti-CDK4 (1:1000), anti-cyclin D1 (1:1000), anti-Akt (1:1000), anti-p-Akt (1:1000) and anti- $\beta$-actin (1:1000). The membrane was visualized using electrochemiluminescence (ECL) Western blot detection reagents (Beyotime, China). Image pro plus 5.02 software (Media Cybernetics, Bethesda, MD, USA) was used to quantify each band intensity. The intensity of each band was normalized to the corresponding intensity of $\beta$-actin or Akt, which was used as a loading control.

\section{Mice and tumor xenografts}

Nude mice were used for xenograft studies with subcutaneous injection of PC-3 cells $\left(1 \times 10^{7}, 0.2 \mathrm{ml}\right.$ per nude mouse). When the tumor grew to $2.0 \times 2.0 \mathrm{~cm}$ size, it was cut into little pieces $(1 \mathrm{~mm} \times 1 \mathrm{~mm} \times 1$ $\mathrm{mm}$ in size), and implanted into another 40 new recipient nude mice. After about 10 days, recipient mice were randomly divided into four groups $(\mathrm{n}=10)$. Among them, formononetin groups respectively received intraperitoneal administration of formononetin $(15,30$ and $60 \mathrm{mg} / \mathrm{kg} / \mathrm{d})$ for 20 days, while the control group received PBS injections. During the 20-day period, the size of tumors was regularly recorded. Then the recipient mice were killed and tumors were excised. The tumor inhibitory rate was calculated by the following formula:

The tumor inhibitory rate $(\%)=1-\left(\mathrm{W}_{\text {treated }} / \mathrm{W}_{\text {control }}\right) \times 100 \%$

\section{Statistical analysis}

All statistical data were expressed as mean \pm standard deviation. Statistical analysis was conducted by one-way ANOVA and Student's t-test using the Statistical Package for Social Sciences (SPSS) 13.0 software. A probability (p)-value $<0.05$ was used as the criterion of statistical significance.

\section{Results}

Inhibited proliferation in both PC-3 and DU145 cells by formononetin

To study the inhibitory effect of formononetin on prostate cancer cells, PC-3 and DU145 cells were respectively treated with various doses of formononetin for $48 \mathrm{~h}$. According to MTT assay, PC-3 cells were more sensitive to formononetin than DU145 cells. As shown in 
Fig. 1. Formononetin inhibited cell proliferation in both PC-3 and DU145 cells. All cells were respectively treated with various concentrations of formononetin for 48 $h$, and then cell viability was determined by MTT assay. 10 independent experiments were repeated. ${ }^{* *} \mathrm{p}<0.05$ vs. control group $(0 \mu \mathrm{M}) ; \mathrm{n}=10$.

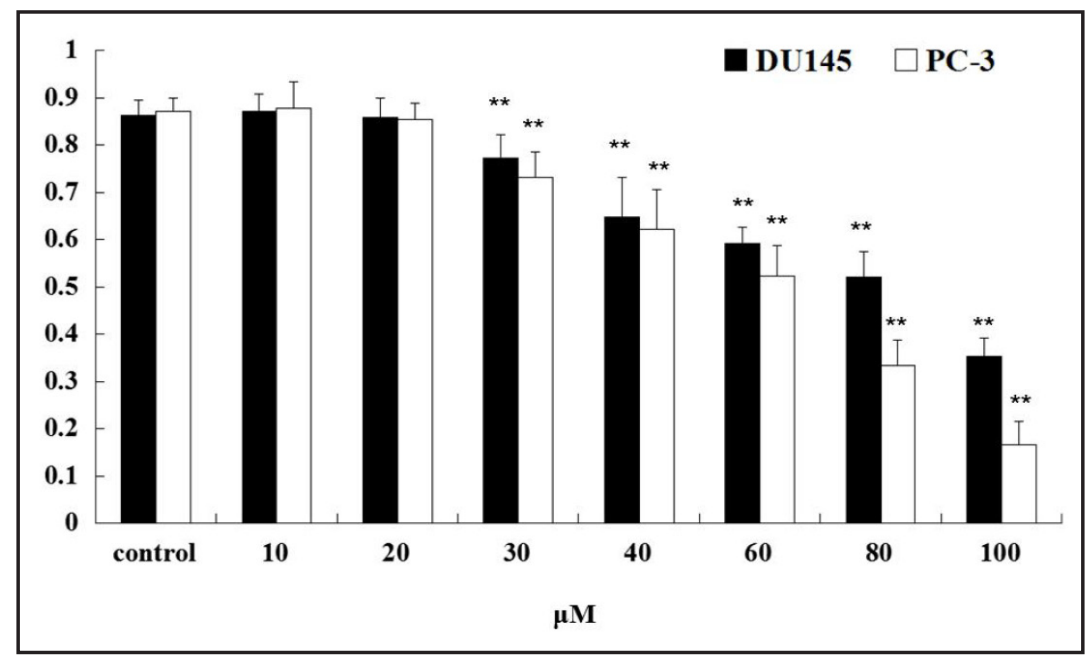

Fig. 2. Formononetin induced cell cycle arrest of PC- 3 cells. Cells were treated with or not treated with formononetin $(0,20,40$ and $80 \mu \mathrm{M}$ ) for $48 \mathrm{~h}$. Then Annexin V-FITC and PI staining followed by flow cytometry were used to assess cell cycle. Data were the mean \pm SD of 3 independent experiments.

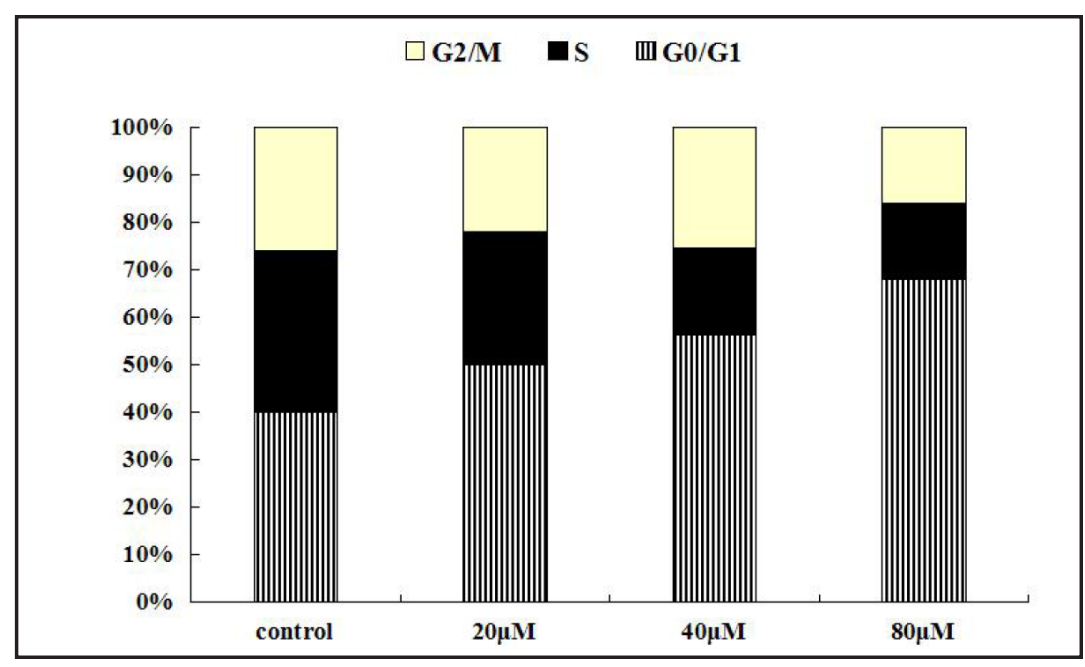

Fig. 1, formononetin inhibited the viability of PC-3 cells in a dose-dependent manner, which remarkably decreased from $0.879 \pm 0.054(0 \mu \mathrm{M})$ to $0.167 \pm 0.048(100 \mu \mathrm{M})(\mathrm{p}<0.05)$. By comparison, the viability of DU145 cells was reduced from $0.871 \pm 0.038(0 \mu \mathrm{M})$ to $0.354 \pm$ $0.0 .037(100 \mu \mathrm{M})$, and obviously lower than that of PC-3 cells under the same conditions. All the above observations suggested the inhibition of formononetin on proliferation of PCa cells. And we preferred to use PC-3 cells rather than DU145 cells in our successive experiments.

\section{Induction of cell cycle arrest in PC-3 cells by formononetin}

To further elucidate how formononetin inhibits the proliferation of PC-3 cells, flow cytometry assay was performed to observe the cell DNA content for assessment of cell cycle in different groups. It was found that the percentage of cells that stayed at the G0/ G1 phase was only $40 \%$ in the vehicle control group $(0 \mu \mathrm{M})$, as shown in Fig. 2. However, formononetin-treated cells showed a gradual increase in the percentage of G0/G1 phase with concentration $(50 \%, 62 \%$ and $68 \%)(p<0.05)$, indicating that formononetin exerts inhibitory effects on PC-3 cells growth via induction of cell cycle arrest.

Downregulation of CDK4 and cyclin D1 mRNA expressions in PC-3 cells by formononetin

PC-3 cells were treated with gradient concentrations of formononetin $(0,25,50$, and $100 \mu \mathrm{M}$ ) for $48 \mathrm{~h}$, and then the mRNA expressions of CDK4 and cyclin D1 were evaluated to explore the potential mechanisms of formononetin-mediated induction of G0/G1 cell cycle arrest. By real-time PCR, we found that the mRNA expression levels of CDK4 and cyclin D1 
a

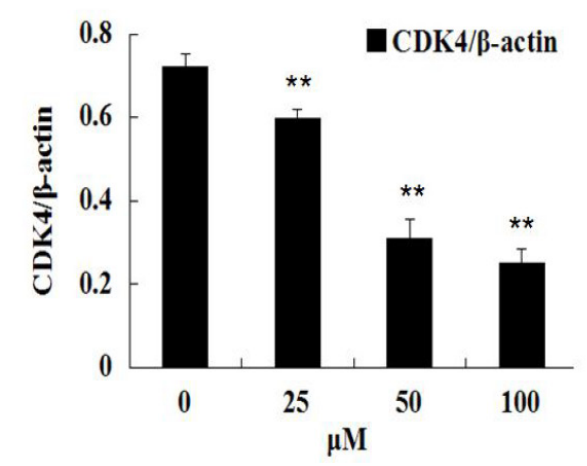

b

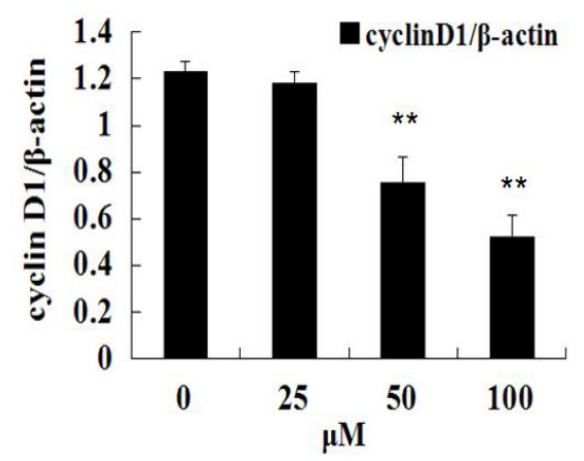

Fig. 3. Formononetin suppressed CDK4 and cyclin D1 mRNA expressions in PC-3 cells. After treatment of formononetin $(0,25,50$ and $100 \mu \mathrm{M})$ for $48 \mathrm{~h}$, the mRNA expression levels of CDK4 and cyclin D1 were determined by real-time PCR. Data were the mean \pm SD of 3 independent experiments. ${ }^{* *} p<0.05$ vs. control group $(0 \mu \mathrm{M}) ; \mathrm{n}=3$.

Fig. 4. Formononetin reduced expression of cyclin D1 and CDK4 proteins, and phosphorylation of Akt in PC-3 cells. Cells were respectively treated with formononetin $(0,20$, 40 and $80 \mu \mathrm{M}$ ) for 48 $h$, and then expression levels of CDK4, cyclin D1 and p-Akt were determined by Western blot (a). The quantification of band intensity relative to $\beta$-actin or Akt were presented as mean $\pm \mathrm{SD}$. ${ }^{* *} \mathrm{p}$ $<0.05$ vs. control group $(0 \mu \mathrm{M}) ; \mathrm{n}=3$.

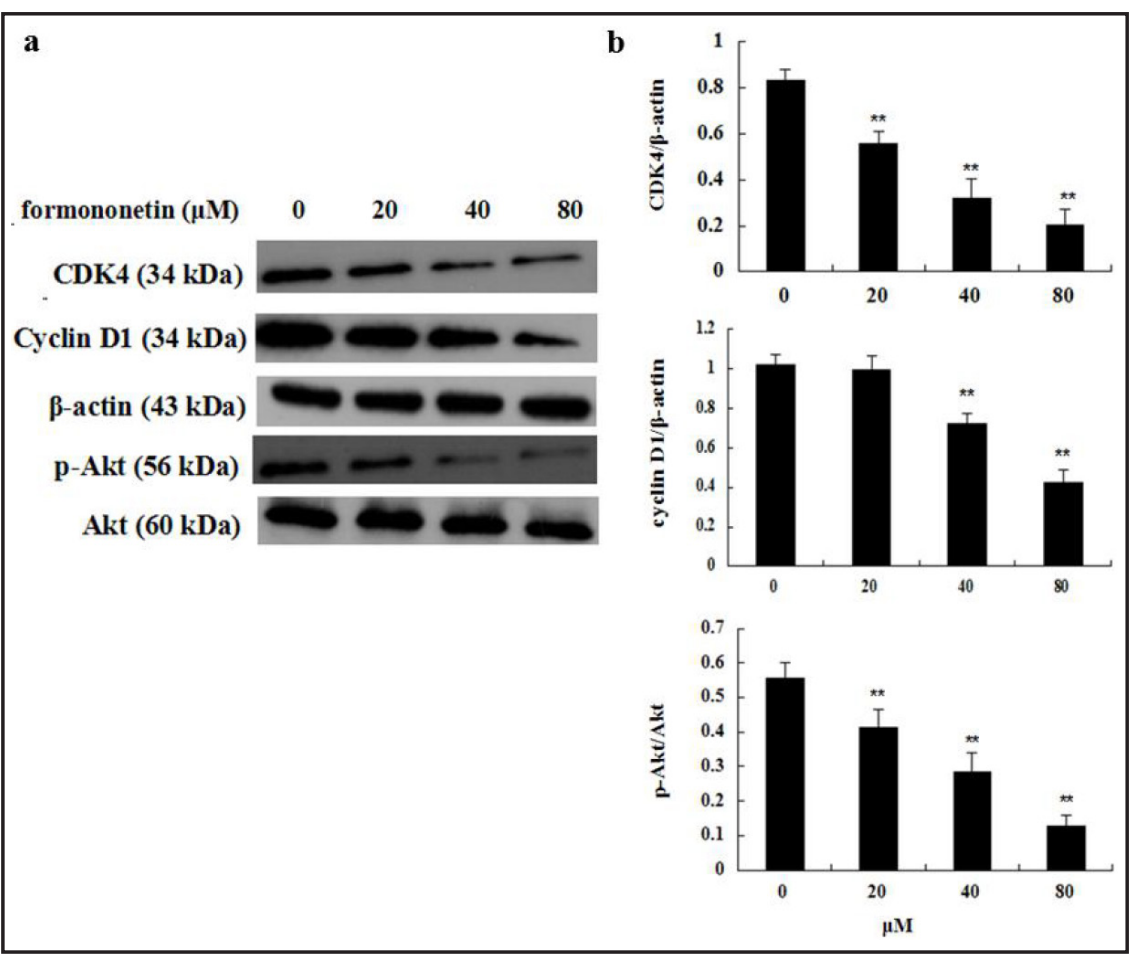

were obviously downregulated by formononetin in a dose-dependent manner $(\mathrm{p}<0.05)$ (Fig. 3).

Reduced protein expressions of CDK4, cyclin D1, and Akt in PC-3 cells by formononetin

Next, western blot analysis was used to confirm the involvement of CDK4 and cyclin D1 in formononetin-induced cell cycle arrest in PC-3 cells, as well as phosphorylation levels of Akt. Consistent with the results above, formononetin $(20,40$ and $80 \mu \mathrm{M})$ markedly and dosedependently reduced the levels of CDK4 and cyclin D1 proteins when compared with the vehicle control group $(0 \mu \mathrm{M})(\mathrm{p}<0.05)$, as shown in Fig. 4. Similarly, Akt was inactivated with the treatment of formononetin in a dose-dependent manner $(p<0.05)$. Overall, these data suggested that the anticancer effects of formononetin on PC-3 cells were highly concerned with the inactivation of CDK4, cyclin D1 and Akt. 
Table 1. Inhibitory effects of formononetin on tumor growth (mean $\pm \mathrm{SD}, \mathrm{n}=10$ ). ${ }^{* *} \mathrm{p}<0.05$ vs. control

\begin{tabular}{|c|c|c|c|c|c|c|}
\hline \multirow[t]{2}{*}{ Group } & \multirow{2}{*}{$\begin{array}{l}\text { Dose } \\
\mathrm{mg} / \mathrm{kg}\end{array}$} & \multirow[t]{2}{*}{$\mathrm{N}$} & \multicolumn{2}{|c|}{ Body Weight(g) } & \multirow{2}{*}{$\begin{array}{c}\text { Tumor weight } \\
\text { (g) }\end{array}$} & \multirow{2}{*}{$\begin{array}{c}\text { Inhibitory } \\
\text { Rate } \\
(\%)\end{array}$} \\
\hline & & & Pre & post & & \\
\hline Control & - & 10 & $20.32 \pm 2.41$ & $27.34 \pm 3.31$ & $1.15 \pm 0.38$ & - \\
\hline Formononetin & 15 & 10 & $19.99 \pm 1.95$ & $26.99 \pm 4.21$ & $1.02 \pm 0.35$ & 0 \\
\hline Form & 30 & 10 & $20.01 \pm 1.55$ & $26.83 \pm 3.72$ & $0.89 \pm 0.22^{* *}$ & 22.61 \\
\hline Formononetin & 60 & 10 & $19.63 \pm 1.46$ & $27.03 \pm 4.23$ & $0.63 \pm 0.35^{* *}$ & 45.22 \\
\hline
\end{tabular}

Suppression of tumor growth in recipient mice by formononetin

Based on the in vitro results, we further assessed the inhibitory effect of formononetin on prostate cancer cells in vivo, in which nude mice bearing tumor xenografts were treated with formononetin or not. Compared with the negative control group, tumor growth was sharply inhibited by formononetin in a dose-dependent manner $(\mathrm{p}<0.05)$, demonstrating its inhibitory effect on PCa growth in vivo (Table 1). And the mean tumor weight in mice treated with formononetin was significantly lower than control group, especially at the dose of $60 \mathrm{mg} / \mathrm{kg}(0.63 \pm 0.35 \mathrm{vs} 1.15 \pm 0.38, \mathrm{p}<0.05)$, with an inhibitory rate up to $45.22 \%$.

\section{Discussion}

As far as we know, the genetic and epigenetic alterations are responsible for the development of prostate cancer through inducing malignant transformation of normal glandular epithelia [17]. Based on its relationship with sex hormone, both estrogen and estrogen receptor (ER) may contribute to prostate carcinogenesis [18-21]. Phytoestrogens, which are increasingly receiving attention for their estrogenic or antiestrogenic effects, play important roles in inhibiting estrogen-dependent tumors via a direct correlation to dosage. In the present study, we also proved that formononetin, a typical phytoestrogen, markedly attenuated the proliferation of PCa cells in a dose-dependent manner in vitro, and this inhibitory effect was more salient in PC-3 cells than DU145 cells. In vivo, formononetin induced a dramatic decrease in tumor weight in the treated mice, further confirming the potential application of formononetin in treating human prostate cancer. A lot of studies demonstrated that the underlying mechanism of dietary phytochemicalsmediated chemopreventive activity may involve the induction of cell cycle arrest $[22,23]$. In accordance with the previous studies, increased cell cycle arrest at G0/G1 phase was found in formononetin-treated human prostate cancer cells, which suggests that the induction of cell cycle arrest may be the major mechanism for its anti-proliferation effect.

Generally speaking, alterations in the genome and protein expressions are crucial to tumor malignant phenotype and progression. Previously, our studies showed that formononetin successfully induced cell cycle arrest at the G0/G1 phase by inactivating IGF1/IGF1R-PI3K/Akt pathways in MCF-7 human breast cancer cells [16]. Thus, we here continued to focus on the molecular mechanism of cell cycle arrest in PCa cells induced by formononetin. The four phases (G1, S, G2, and M phases) of the cell cycle are sequentially transitioned in response to growth factor or oncogenic stimulation, including cyclins, the regulatory units, and cyclin-dependent kinases (CDKs), the catalytic units [24, 25]. Among them, cyclin $\mathrm{D}$ and $\mathrm{E}$, together with CDK2, CDK4, or CDK6, play major parts in the replication of DNA and mitosis via the regulation of G0/G1 phase of the cell cycle [26]. And overactivation of cyclins and CDKs can provide cancer cells a selective growth advantage [27]. Cyclin D1 is considered as a mitogenic sensor that relays and amplifies extracellular growth signals [28]. By activating its partner kinases, CDK4, elevated cyclin D1 is known to shorten the cell-cycle length, directly contributing to G0/G1 cell cycle arrest and the proliferation of many human cancer cells such as cancers of the breast $[29,30]$. Accordingly, targeting cyclin D1/CDK4 complexes may be a potential way to treat prostate cancer. As expected, we here found that formononetin significantly block the expression of cyclin D1 and CDK4 (reduction in mRNA 
and protein) in a dose-dependent manner in PC-3 cells, in concordance with increased G0/ G1 cell cycle arrest.

PI3K/Akt signaling pathway is an important intracellular signal transduction pathway, participating in regulation of cell apoptosis and proliferation. Akt, a promoter of cell proliferation and survival, is found to be overexpressed in the tumor formation, implying that inactivation of Akt may prevent the development and progression of cancers [31]. Previous studies suggest that the activation of Akt could impair phosphorylation of glycogen synthase kinase (GSK) $3 \beta$, followed by increased expression of cyclin D1, facilitating the G1/S progression of cell cycle [32]. In the present study, inactivation of Akt in PC-3 cells was demonstrated with treatment of formononetin, which is consistent with formononetintriggered degradation of cyclin D1 and CDK4. Thereby, we conclude that formononetin arrests cell cycle progression at G0/G1 phase by downregulating the phosphorylation state of Akt, and subsequently decreasing the levels of cyclin D1 and CDK4 expression.

Taken together, these findings indicate that formononetin exhibits anti-tumor effects on human prostate cancer cells by leading to G0/G1 cell cycle arrest, which is mediated by inhibiting Akt-mediated signaling pathways and blocking the expressions of cyclin D1/CDK4 complexes. Considering the wide application of red clover plants in clinical, formononetin may be a promising antiproliferative agent for the treatment of prostate cancer.

\section{Acknowledgments}

This work was supported by a grant from National Natural Science Foundation of China (81260376) and Natural Scientific Foundation of Guangxi (2013GXNSFAA019122).

\section{Reference}

$>_{2}$

$>3$

$\checkmark 4$

$>5$

- 6

- 7

$>8$

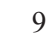

$>10$

$>11$

$>12$

13

Hsing AW, Chokkalingam AP: Prostate cancer epidemiology. Front Biosci 2006;11:1388-1413. Gomella LG, Johannes J, Trabulsi EJ: Current prostate cancer treatments: effect on quality of life. Urology 2009;73:S28-S35.

Jemal A, Siegel R, Ward E, Hao Y, Xu J, Murray T, Thun MJ: Cancer statistics, 2008. CA Cancer J Clin 2008;58:71-96.

Hemminki K, Rawal R, Bermejo JL: Prostate cancer screening, changing age-specific incidence trends and implications on familial risk. Int J Cancer 2005;113:312-315.

McDavid K, Lee J, Fulton JP, Tonita J, Thompson TD: Prostate cancer incidence and mortality rates and trends in the United States and Canada. Public Health Rep 2004;119:174-186.

Wolk A: Diet, lifestyle and risk of prostate cancer. Acta Oncol 2005;44:277-281.

Chen J, Liu L, Hou R, Shao Z, Wu Y, Chen X, Zhou L: Calycosin promotes proliferation of estrogen receptorpositive cells via estrogen receptors and ERK1/2 activation in vitro and in vivo. Cancer Lett 2011;308:144151.

Zhao R, Xiang N, Domann FE, Zhong W: Effects of selenite and genistein on G2/M cell cycle arrest and apoptosis in human prostate cancer cells. Nutr Cancer 2009;61:397-407.

Mu H, Bai YH, Wang ST, Zhu ZM, Zhang YW: Research on antioxidant effects and estrogenic effect of formononetin from Trifolium pratense (red clover). Phytomedicine 2009;16:314-319.

Zhang S, Tang X, Tian J, Li C, Zhang G, Jiang W, Zhang Z: Cardioprotective effect of sulphonated formononetin on acute myocardial infarction in rats. Basic Clin Pharmacol Toxicol 2011;108:390-395.

Fang SC, Hsu CL, Lin HT, Yen GC: Anticancer effects of flavonoid derivatives isolated from Millettia reticulata Benth in SK-Hep-1 human hepatocellular carcinoma cells. J Agric Food Chem 2010;58:814-820.

Auyeung KK, Ko JK: Novel herbal flavonoids promote apoptosis but differentially induce cell cycle arrest in human colon cancer cell. Invest New Drugs 2010;28:1-13.

Gyémánt N, Tanaka M, Antus S, Hohmann J, Csuka O, Mándoky L, Molnár J: In vitro search for synergy between flavonoids and epirubicin on multidrug-resistant cancer cells. In Vivo 2005;19:367-374. 
Li et al.: Formononetin Promotes Cell Cycle Arrest

14 Seo EK, Kim NC, Mi Q, Chai H, Wall ME, Wani MC, Navarro HA, Burgess JP, Graham JG, Cabieses F, Tan GT, Farnsworth NR, Pezzuto JM, Kinghorn AD: Macharistol, a new cytotoxic cinnamylphenol from the stems of Machaerium aristulatum. J Nat Prod 2001;64:1483-1485.

15 Huang WJ, Bi LY, Li ZZ, Zhang X, Ye Y: Formononetin induces the mitochondrial apoptosis pathway in prostate cancer cells via downregulation of the IGF-1/IGF-1R signaling pathway. Pharm Biol 2014;52: 466470.

16 Chen J, Zeng J, Xin M, Huang W, Chen X: Formononetin induces cell cycle arrest of human breast cancer cells via IGF1/PI3K/Akt pathways in vitro and in vivo. Horm Metab Res 2011;43:681-686.

17 Konishi N, Shimada K, Ishida E, Nakamura M: Molecular pathology of prostate cancer. Pathol Int 2005;55:531-539.

18 Smith S, Sepkovic D, Bradlow HL, Auborn KJ: 3,3'-Diindolylmethane and genistein decrease the adverse effects of estrogen in LNCaP and PC-3 prostate cancer cells. J Nutr 2008;138:2379-2385.

19 Hara T, Miyazaki H, Lee A, Tran CP, Reiter RE: Androgen receptor and invasion in prostate cancer. Cancer Res 2008;68:1128-1135.

20 Suzuki H, Ueda T, Ichikawa T, Ito H: Androgen receptor involvement in the progression of prostate cancer. Endocr Relat Cancer 2003;10:209-216.

-21 Linja MJ, Savinainen KJ, Tammela TL, Isola JJ, Visakorpi T: Expression of ERalpha and ERbeta in prostate cancer. Prostate 2003;55:180-186.

22 Pan MH, Ghai G, Ho CT: Food bioactives, apoptosis, and cancer. Mol Nutr Food Res 2008;52:43-52.

23 Pan MH, Ho CT: Chemopreventive effects of natural dietary compounds on cancer development. Chem Soc Rev 2008;37:2558-2574.

24 Hilakivi-Clarke L, Wang C, Kalil M, Riggins R, Pestell RG: Nutritional modulation of the cell cycle and breast cancer. Endocr Relat Cancer 2004;11:603-622.

-25 Gulappa T, Reddy RS, Suman S, Nyakeriga AM, Damodaran C: Molecular interplay between cdk4 and p21 dictates G0/G1 cell cycle arrest in prostate cancer cells. Cancer Lett 2013;337:177-183.

26 Vermeulen K, Van Bockstaele DR, Berneman ZN: The cell cycle: a review of regulation, deregulation and therapeutic targets in cancer. Cell Prolif 2003;36:131-149.

27 Hall M, Peters G: Genetic alterations of cyclins, cyclin-dependent kinases, and Cdk inhibitors in human cancer. Adv Cancer Res 1996;68:67-108.

28 Hilakivi-Clarke L, Wang C, Kalil M, Riggins R, Pestell RG: Nutritional modulation of the cell cycle and breast cancer. Endocr Relat Cancer 2004;11:603-622.

29 Dickson MA, Schwartz GK: Development of cell-cycle inhibitors for cancer therapy. Curr Oncol 2009;16:3643.

30 Hallstrom TC, Nevins JR: Balancing the decision of cell proliferation and cell fate. Cell Cycle 2009;8:532535.

-31 Serrano ML, Sánchez-Gómez M, Bravo MM, Yakar S, LeRoith D: Differential expression of IGF-I and insulin receptor isoforms in HPV positive and negative human cervical cancer cell lines. Horm Metab Res 2008;40:661-667.

-32 Ma X, Hu Y: Targeting PI3K/Akt/mTOR cascade: the medicinal potential, updated research highlights and challenges ahead. Curr Med Chem 2013;20:2991-3010. 